\title{
Sex differences in Hippocampal Memory and Learning following Neonatal Brain Injury: Is There a Role for Estrogen Receptor-a?
}

\author{
Dila Zafer ${ }^{\mathrm{a}}$ Nur Aycan ${ }^{\mathrm{a}}$ Burak Ozaydin ${ }^{\mathrm{a}}$ Pinar Kemanli $^{\mathrm{a}}$ \\ Peter Ferrazzano ${ }^{a, b}$ Jon E. Levine ${ }^{c, d}$ Pelin Cengiz ${ }^{a, b}$ \\ ${ }^{a}$ Waisman Center, University of Wisconsin, Madison, WI, USA; ${ }^{b}$ Division of Pediatric Critical Care Medicine, \\ Department of Pediatrics, University of Wisconsin, Madison, WI, USA; ' ${ }^{C}$ Department of Neuroscience, University of \\ Wisconsin, Madison, WI, USA; ${ }^{d}$ Wisconsin National Primate Research Center, Madison, WI, USA
}

\section{Keywords}

Neonate $\cdot$ Estrogen receptor-a $\cdot$ Sex differences .

Hippocampus · Hypoxia-ischemia - Encephalopathy ·

Tyrosine kinase receptor

\begin{abstract}
Neonatal encephalopathy due to hypoxia-ischemia (HI) leads to severe, life-long morbidities in thousands of neonates born in the USA and worldwide each year. Varying capacities of long-term episodic memory, verbal working memory, and learning can present without cerebral palsy and have been associated with the severity of neonatal encephalopathy sustained at birth. Among children who sustain a moderate degree of $\mathrm{HI}$ at birth, girls have larger hippocampal volumes compared to boys. Clinical studies indicate that female neonatal brains are more resistant to the effects of neonatal HI, resulting in better long-term cognitive outcomes compared to males with comparable brain injury. Our most recent mechanistic studies have addressed the origins and cellular basis of sex differences in hippocampal neuroprotection following neonatal HI-related brain injury and implicate estrogen receptor- $a(E R a)$ in the neurotrophin receptor-mediated hippocampal neuroprotection in female mice. This review
\end{abstract}

\section{KARGER}

(C) 2019 S. Karger AG, Basel

E-Mail karger@karger.com

www.karger.com/nen summarizes the recent findings on ERa-dependent, neurotrophin-mediated hippocampal neuroprotection and weighs the evidence that this mechanism plays an important role in preservation of long-term memory and learning following $\mathrm{HI}$ in females.

(c) 2019 S. Karger AG, Basel

\section{Introduction}

Neonatal encephalopathy due to hypoxia-ischemia (HI) leads to severe, life-long morbidities in thousands of neonates born in the US and worldwide each year $[1,2]$. The severe morbidities following neonatal encephalopathy include but are not limited to cerebral palsy (CP), epilepsy, cognitive impairment, and memory deficits [2]. Interestingly, cognitive impairments can take place in the absence of motor deficits seen in patients with cerebral palsy [3]. In fact, varying capacities of long-term episodic memory, verbal working memory, and learning can present without $\mathrm{CP}$ and have been associated with the severity of neonatal encephalopathy sustained at birth [4].

Dila Zafer and Nur Aycan contributed equally to this work. 


\section{Hippocampal Impairment following HI in Human \\ Neonates}

Several studies in humans have implicated hippocampal injury in episodic memory deficits following neonatal HI. In fact, bilateral severe hippocampal atrophy determined by quantitative MRI imaging studies is a common finding among survivors of neonatal HI [5]. Hippocampal injury in school age children results in visuospatial memory deficits, leading to difficulties in acquiring new information, learning at a slower pace, and a need for repeated exposure to new information in school age children [6]. Interestingly, in a cohort of children who sustained a moderate degree of $\mathrm{HI}$ at birth and underwent MRI at 9-10 years of life, girls had a greater hippocampal volume compared to boys [3]. In the same study, although the intelligence quotient was not found to be different between the girls and the boys, visuospatial long-term memory deficits correlated with hippocampal volumes, indicating better outcomes in girls [3].

\section{Is Hippocampal Neuroprotection following HI Greater} in Female versus Male Human Neonates?

Clinical studies indicate that female neonatal brains are more resistant to the effects of neonatal HI, resulting in better long-term cognitive outcomes as compared to males with comparable brain injury [7-14]. The relative resistance of the neonatal female brain to HI suggests that some sex-specific mechanisms afford females greater neuroprotection and/or facilitate recovery [7]. The molecular and cellular mechanisms that mediate femalebiased hippocampal neuroprotection in neonates are not well understood, representing a critical knowledge gap that currently limits the development of treatment strategies that could be based on amplification of these neuroprotective responses. Our most recent mechanistic studies aim to address the origins and cellular basis of sex differences in hippocampal neuroprotection following neonatal HI-related brain injury and implicate estrogen receptor- $\alpha(E R \alpha)$ in neurotrophin receptor-mediated hippocampal neuroprotection in females.

This review summarizes the recent findings on ER $\alpha$ dependent, neurotrophin-mediated hippocampal neuroprotection and weighs the evidence that this mechanism plays an important role in preserving long-term memory and learning following $\mathrm{HI}$ in females. Elucidation of the mechanisms underlying female-specific neuroprotective responses that may be lacking in male brains may provide the foundational insights necessary for future development of novel sex-specific therapies targeting the hippocampus [15].
Neurotrophin Receptors Mediate Female-Specific Hippocampal Neuroprotection following HI

Neurotrophins are growth factors that regulate the development and maintenance of the central nervous system. Much attention has been focused on putative roles of neurotrophins and their receptors in neuroprotection and recovery from injury following adult stroke and neonatal HI $[11,12,16]$. The most extensively studied endogenous neurotrophin, i.e., brain-derived neurotropic factor (BDNF), has been shown to bind and induce phosphorylation of tyrosine kinase B receptors (TrkB) in hippocampal cells, reduce the infarct volume by $55 \%$ [17], and improve visuospatial learning following neonatal HI [18]. While these endogenous neurotrophins contribute to hippocampal neuroprotection after ischemia, the clinical utility of neurotrophin therapies has been limited by their susceptibility to enzymatic degradation and poor bioavailability compounded by concerns that their nonspecific affinity for other receptors such as the p75 receptor may exacerbate neuronal damage $[19,20]$. Accordingly, clinical trials of neurotrophins, including BDNF, as therapy for various neurological diseases have been universally disappointing $[21,22]$. Efforts have therefore been made to find nonpeptide, small molecule ligands capable of specifically activating TrkB signaling with a high specificity and potency and improved bioavailability that might serve as an alternative to BDNF [23]. Recently, a selective and potent TrkB agonist, i.e., 7,8-dihydroxyflavone (7,8DHF), was identified to cross the blood-brain barrier with a high bioavailability and phosphorylate $\operatorname{TrkB}[16,24,25]$. Early neuroprotective effects of 7,8-DHF as a TrkB agonist have been reported in adult male mice after transient middle cerebral artery occlusion (MCAO) and in hippocampal neurons [16]. We have similarly found that 7,8-DHF exerts a profound early and late neuroprotective effect in neonatal mice following in vivo $\mathrm{HI}$ by phosphorylating the full-length TrkB [11]. However, this protection was confined to female mice only, while male mice derived no benefit from 7,8-DHF treatment $[11,12]$. Thus, 7,8-DHF fully mimics the effects of BDNF as a selective and potent TrkB agonist and reveals a sex difference in neurotrophin receptor-mediated neuroprotection following neonatal HI. This neuroprotection appears to be due to the significantly increased phosphorylation of TrkB we found in the hippocampus of 7,8-DHF-treated female mice [11, 12].

\section{Female-Specific Hippocampal Neuroprotection}

following Neonatal HI Requires ER $\alpha$

We have contributed to a growing body of literature demonstrating the importance of estrogen receptor signal- 
ing in response to cerebral ischemia [12,26-28]. The role of estrogen receptors such as ER $\alpha$ and ER $\beta$ in the mammalian hippocampus has been studied in neonatal and adult rodent models of cerebral ischemia [12, 29, 30]. Following focal ischemia in adult rodents, the expression of ERa and ER $\beta$ showed different patterns, with upregulation of ERa expression early after injury followed by a later increase in $E R \beta$ expression [29]. In a study which established the neuroprotective effects of estradiol after focal ischemia, deletion of ER $\alpha$ abolished the protective actions of estradiol in all regions of the brain, whereas ablation of ER $\beta$ had no effect on neuroprotection by estradiol. Similarly, neuroprotective effects of estradiol in ovariectomized adult female rodents following MCAO have been found to be dependent on ER $\alpha$ but not on ER $\beta$ [29], and selective deletion of neuronal ERa prevents estradiol-dependent neuroprotection after MCAO. Thus, ERa is critical in mediating the protective effects of physiologic levels of estradiol following cerebral ischemia in adult female rodents $[28,30]$. Additionally, ERa expression is differentially increased in adult females compared to adult males in ischemic cortical brain regions after MCAO [31]. Interestingly, following neonatal HI, the expression of ER $\alpha$ mRNA and protein but not ER $\beta$ is increased in the female hippocampus compared to corresponding sham mice [12].

Both ER $\alpha$ and ER $\beta$ have been shown to play an important role in hippocampal-dependent memory and learning [32]. However, the regional distribution and time course of expression differ between ER $\alpha$ and ER $\beta$ depending on the age at injury (neonatal, adult, or postmenopausal), suggesting that they have different functions under different physiological and pathological conditions. For instance, periodic treatment of ovariectomized young and senescent female rodents with an ER $\beta$ agonist following MCAO decreased blood-brain barrier breakdown and cell death, resulting in improved hippocampal-dependent spatial memory and learning [33-35]. In contrast, following neonatal $\mathrm{HI}$ in mice, the expression of hippocampal $\mathrm{ER} \alpha$, but not $\mathrm{ER} \beta$, increases in the female hippocampus and it is associated with decreased apoptosis [12]. This region-specific sexually differential ERa upregulation was not observed in the diencephalon and forebrain of neonatal rats 4 days following injury [36]. Thus, attention must be paid to the region-, age-, sex- and model-specific mechanisms by which ERa activation confers hippocampal neuroprotection following cerebral ischemia.

Estradiol is one of the most commonly studied ligands of the ER in the hippocampus, and measurements of estradiol content have not revealed any sex differences over the developmental life span of a rodent [37]. Despite the absence of sex differences during normal brain development, recent studies conducted in zebra finch have implicated estradiol synthesized in reactive astrocytes as the locally produced ligand for estrogen receptors following brain injury $[38,39]$. Sex differences seen following brain injury in zebra finch were attributed to rapid astrocytic aromatase induction leading to estradiol production in female zebra finch brains. This rapid aromatization to estradiol leads to decreased neuronal inflammation and increased neuronal survival in females but not in males [40]. Following neonatal HI, the estradiol content did not increase or differ between the sexes in the diencephalon and forebrain over the course of 4 days following injury [36]. Administration of estradiol as a neuroprotective strategy following neonatal $\mathrm{HI}$ has revealed conflicting and inconclusive results [41, 42]. Most recently, exogenous estradiol administration was shown to increase long-term neurogenesis and improve behavioral outcomes in both males and females but did not improve hippocampal atrophy after an ischemic injury [43]. Taken together, the time course and cellular origins of the hippocampal ER response to neonatal $\mathrm{HI}$ in male and female neonates need to be studied further.

\section{Female-Specific Responsiveness to TrkB Agonist}

following Neonatal HI Requires ER $\alpha$

We recently demonstrated that in vivo $\mathrm{HI}$ induces a sex-specific increase in TrkB phosphorylation in the female, but not the male, neonatal hippocampus $[11,12]$. Additionally, treatment with the TrkB agonist 7,8-DHF enhances this HI-induced hippocampal TrkB phosphorylation only in females [12] and results in a profound improvement in hippocampal neuronal survival, again only in females [11]. This rapid enhancement in hippocampal TrkB phosphorylation following $\mathrm{HI}$ also results in longterm improvement in hippocampus-dependent visuospatial memory in only young adult female mice. We went on to investigate the role of ERa in TrkB-mediated neuroprotection and found that the female-specific TrkB phosphorylation and decreased apoptosis after 7,8-DHF treatment was eliminated in ER $\alpha$-null mutant mice [12]. Thus, for the first time following neonatal HI, we showed that the female-specific responsiveness to TrkB agonist therapy in hippocampal neuroprotection is dependent upon ERa expression. In particular, important mechanistic questions remain to be answered, including whether nuclear or membrane ERa is responsible for ER-mediated responses to ischemia and whether ERa activation occurs in a ligand-dependent or a ligand-independent way leading to TrkB phosphorylation (Fig. 1). 
Fig. 1. Working hypothesis. HI induces upregulation of the ER $\alpha$ in the female hippocampus (1). This upregulation might be influenced by neonatal hormonal environment (T) and/or epigenetic regulation of the ER $\alpha$ gene promoter regions. The membrane-initiated, nongenomic ERa signaling (2) may occur in a ligand-dependent or ligand-independent way (3); phosphorylation of SFK (4) leads to TrkB receptor phosphorylation (5). The addition of TrkB agonist (7,8-dihydroxyflavone) increases the phosphorylation of TrkB, which in turn activates downstream signaling pathways, resulting in decreased apoptosis (6) and neuroprotection (7).

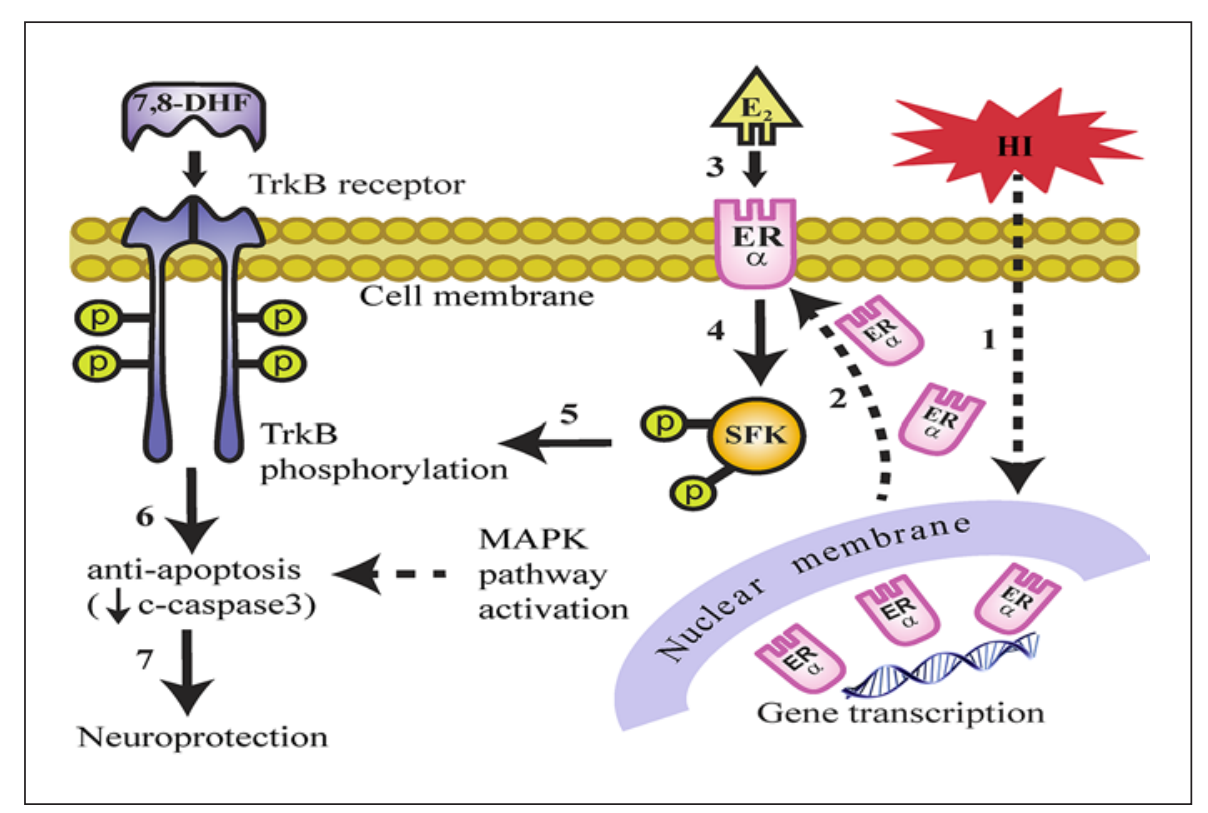

Neurotrophin-Mediated Neuroprotection Is

Dependent on ER $\alpha$ : What Are the Intracellular

Signaling Pathways for ER $\alpha$-TrkB Crosstalk?

There is increasing evidence that rapid nongenomic signaling via membrane-localized extranuclear estrogen receptors may contribute to neuroprotection in the brain [44]. A link between ERa expression and TrkB signaling is suggested by the finding that estradiol treatment induces phosphorylation of TrkB in the adult mouse hippocampi, and this response is absent in ER $\alpha$-null mutant mice [45]. Estradiol rapidly activates membrane-associated ERa coupled to intracellular signaling via Src family kinases (SFK) [46]. SFK are a family of nonreceptor tyrosine kinases that have been implicated in regulation of diverse physiological and pathological processes in the nervous system as well as other organs, and they have been shown to augment the phosphorylation of TrkB receptors $[46,47]$. We recently showed that $\mathrm{HI}$ and 7,8DHF treatment induces Src phosphorylation in an ERadependent manner [12]. A physical association of estrogen receptors with nerve growth factor receptor and Src has also been described [48-50].

Recent evidence suggests that the interplay of ERa with growth factor receptor pathways influences tumor growth in certain cancers [46]. In these cancers, activation of SFK was proposed to mediate crosstalk between ER $\alpha$ and TrkB [46]. Once activated by ER $\alpha$, SFK phosphorylate the cytoplasmic tyrosine residues of TrkB ${ }^{\mathrm{y} 705}$ leading to activation of cell survival pathways such as mitogen-activated protein kinase (MAPK) pathway [46, 49,
50]. Interestingly, both $\operatorname{TrkB}$ and ERa activate similar downstream survival pathways, such as the Ras-MAPK pathways $[16,51,52]$. In cultured cortical neuronal cells, administration of BDNF increased the phosphorylation of TrkB resulting in activation of the MAPK pathway and neuroprotection following in vitro hypoxia [52]. Similarly, in hippocampal neurons following in vitro HI, phosphorylation of TrkB via 7,8-DHF administration, in the absence of BDNF, resulted in activation of the MAPK pathway and decreased apoptosis [16]. Following neonatal $\mathrm{HI}$ in rodents, phosphorylation of TrkB via intracerebroventricular administration of BDNF decreased the caspase 3-mediated apoptosis and increased the phosphorylation of MAPK-ERK1/2 in cortical and hippocampal neurons. These beneficial effects of BDNF administration were blocked by inhibition of the MAPK-ERK1/2 pathway but not the PI3-kinase pathway [53]. Similarly, estradiol acts via estrogen receptors, growth factor receptors, and MAPK/ERK signaling to promote hippocampal neuronal survival following global ischemia $[54,55]$. Activation of the tyrosine kinase and Src represents one of the initial steps in ERa-mediated cell signaling and neuroprotection [56]. However, the intracellular mechanisms by which ERa signaling influences and activates the membrane-localized TrkB in the neonate hippocampi are currently unknown. It is possible that the ERa signaling in this context occurs mainly through rapid nongenomic, nonclassical signaling via $\mathrm{ERa}$ complexed with caveolar proteins at the plasma membrane $[57,58]$. We have reported that: (1) BDNF expression is not increased in the 
female hippocampus following neonatal HI, effectively ruling out an altered ligand production as a source of neuroprotection [12]; (2) unlike ER $\alpha$ upregulation, $E R \beta$ is not upregulated [12]; (3) and phosphorylated $\mathrm{Src}^{\mathrm{y} 418}$ expression is upregulated only in female neonatal mice hippocampi following $\mathrm{HI}$ and 7,8-DHF treatment in an ERadependent manner [12]. Taken together, these findings support the hypothesis that coupling of non-genomic, membrane-initiated ERa signaling to TrkB phosphorylation in neonatal hippocampi following $\mathrm{HI}$ might be mediated by Src, ultimately resulting in increased neuronal survival (Fig. 1). However, the functional interplay of $\mathrm{ER} \alpha, \mathrm{Src}$, and TrkB signaling is not completely understood. It remains to be determined whether membranelocalized ERa is integral to TrkB-mediated neuroprotection and whether Src mediates this crosstalk in the hippocampus following $\mathrm{HI}$.

\section{Neonatal HI Induces ER $\alpha$ Expression in Female, but}

Not Male, Hippocampi: Are Epigenetic Mechanisms Involved?

$\mathrm{ER} \alpha$ is equally expressed at baseline in male and female rat [59-61] and sham-operated mouse [12] hippocampi. Recent studies have provided evidence that upregulation of ERa in response to brain injury or an environmental stimulus, such as maternal grooming, may be mediated by epigenetic alterations to the ERa gene promoter [62]. We and others have demonstrated that cerebral ischemia induces upregulation of ERa mRNA and protein expression in the ischemic brain regions of females only $[12,31]$.

Upregulation of ERa in response to brain injury may be mediated by epigenetic alterations to the ERa gene promoter in a sex-specific manner. This was most clearly demonstrated by the finding that DNA methylation of the ERa promotor is decreased in the cerebral cortex following ischemia only in adult female rodents, likely resulting in upregulation of the ERa [31]. This data suggests that there might be some epigenetic modifications playing a role in upregulation of ER $\alpha$ after a significant stress such as brain injury. To determine whether sexspecific ERa upregulation is mediated by HI-induced DNA demethylation, and hence decreased repression of the ERa promoter, we investigated mRNA expression levels of a panel of DNA methylating and demethylating enzymes in the hippocampus of male and female neonatal mice after HI. We did not observe any sex differences on day 1 or day 3 after HI among this panel of enzymes that are involved in DNA methylation or demethylation including tet 1 , tet 2 , dnmt 1 , dnmt $3 a$, and dnmt3b (un- publ. data) [63]. Interestingly, only the demethylating DNA repair enzyme, Gadd45b mRNA, and protein expression were significantly upregulated in the female hippocampus compared to the male hippocampus 1 day after HI. This is consistent with the finding from other studies that in P7 rats Gadd45b responds to DNA damage as part of the DNA repair response [64] and that Gadd45b is expressed in sublethally injured neurons in the infarct and peri-infarct regions after MCAO [64]. However, further studies are needed to fill the knowledge gap in the epigenetic mechanisms that may play a role in the upregulation of ERa in neonatal female hippocampi and identify what mechanism is deficient in male mice to improve the neurological outcomes following neonatal HI (Fig. 1).

\section{HI Induces Sex-Dependent ER $\alpha$ Expression and}

Neuroprotection: Does the Perinatal Hormone

Environment Program Subsequent ER $\alpha$ Expression in

Response to HI?

Classic studies of sex differences in brain structure and function in rodents have demonstrated that the perinatal hormone environment - characterized by a surge in testosterone $(\mathrm{T})$ in males and the absence of a $\mathrm{T}$ surge in females - programs the development of some neuronal circuitries that support sex-specific behaviors and physiological functions in adulthood [65]. The perinatal hormonal environment is characterized by 2 surges of $\mathrm{T}$ in male mice in utero at E13 and at birth $0-4 \mathrm{~h}$ postnatally, while females demonstrate low $\mathrm{T}$ levels throughout the embryonic and perinatal period $[66,67]$. While the embryonic $\mathrm{T}$ surge is responsible for gonadal development, this male-specific perinatal $\mathrm{T}$ surge at birth has been linked to masculinization of neuronal morphology and behavior [13], and many sex differences in response to environmental or somatic stimuli have been shown to be established by the organizational effects of $\mathrm{T}$, or its absence, in the perinatal environment [65]. These sex differences in perinatal hormonal environment have been proposed to underlie the clinical observation that male infants suffer more severe cognitive deficits, language delays, and learning disorders than girls with comparable brain injury [13].

The effects of $\mathrm{T}$ following neonatal $\mathrm{HI}$ have been studied. $\mathrm{T}$ exposure at birth results in worsened neurologic outcomes following subsequent $\mathrm{HI}$ in newborn female rodents [13]. These female newborn pups that are exposed to $\mathrm{T}$ at birth showed worsening of the brain injury and impaired behavioral outcome after HI, effectively equalizing the brain injury to that seen in males [13]. The 
role of the perinatal hormone environment in programming sex-specific ERa expression and hippocampal neuroprotection following $\mathrm{HI}$ needs to be further assessed in order to better understand the effect of embryonic and perinatal $\mathrm{T}$ exposure in males.

\section{Conclusion}

Studies that directly address the origins and cellular basis of sex differences in neuroprotection following neonatal encephalopathy due to HI will help guide further research into sex-specific therapies for developmental brain injury [15]. Discovering the cellular mechanisms by which ER $\alpha$ confers female-specific hippocampal neuro- protection after $\mathrm{HI}$ will provide new information needed to develop novel therapeutic approaches in both sexes. In addition, these findings may have broad application to other important pediatric disorders in which $\operatorname{TrkB}$ is known to play an important role such as childhood psychiatric disorders [68-70], neuroblastomas [71], and Rett syndrome $[72,73]$.

\section{Acknowledgment}

We would like to acknowledge NIH/NINDS K08NS088563-01 (P. Cengiz), NIH/NINDS K08NS078113 (P. Ferrazzano), a Department of Pediatrics Research and Development Grant (P. Cengiz and P. Ferrazzano), and NIH grant P30 HD03352 (Waisman Center).

\section{References}

1 Drobyshevsky A, Derrick M, Wyrwicz AM, Ji $\mathrm{X}$, Englof I, Ullman LM, et al. White matter injury correlates with hypertonia in an animal model of cerebral palsy. J Cereb Blood Flow Metab. 2007 Feb;27(2):270-81.

2 Ferriero DM. Neonatal brain injury. N Engl J Med. 2004 Nov;351(19):1985-95.

3 Annink KV, de Vries LS, Groenendaal F, van den Heuvel MP, van Haren NE, Swaab H, et al. The long-term effect of perinatal asphyxia on hippocampal volumes. Pediatr Res. 2018 Jan;85(1):43-9.

4 van Handel M, Swaab H, de Vries LS, Jongmans MJ. Long-term cognitive and behavioral consequences of neonatal encephalopathy following perinatal asphyxia: a review. Eur J Pediatr. 2007 Jul;166(7):645-54.

5 Gadian DG, Aicardi J, Watkins KE, Porter DA, Mishkin M, Vargha-Khadem F. Developmental amnesia associated with early hypoxic-ischaemic injury. Brain. 2000 Mar; 123 (Pt 3):499-507.

6 Elward RL, Vargha-Khadem F. Semantic memory in developmental amnesia. Neurosci Lett. 2018 Jul;680:23-30.

7 Hill CA, Fitch RH. Sex differences in mechanisms and outcome of neonatal hypoxia-ischemia in rodent models: implications for sexspecific neuroprotection in clinical neonatal practice. Neurol Res Int. 2012;2012:867531.

8 Vannucci SJ, Hurn PD. Gender differences in pediatric stroke: is elevated testosterone a risk factor for boys? Ann Neurol. 2009 Dec;66(6): 713-4.

9 Marlow N, Rose AS, Rands CE, Draper ES. Neuropsychological and educational problems at school age associated with neonatal encephalopathy. Arch Dis Child Fetal Neonatal Ed. 2005 Sep;90(5):F380-7.
10 Tioseco JA, Aly H, Essers J, Patel K, El-Mohandes AA. Male sex and intraventricular hemorrhage. Pediatr Crit Care Med. 2006 Jan; 7(1):40-4.

11 Uluc K, Kendigelen P, Fidan E, Zhang L, Chanana $V$, Kintner D, et al. TrkB receptor agonist 7, 8 dihydroxyflavone triggers profound gender- dependent neuroprotection in mice after perinatal hypoxia and ischemia. CNS Neurol Disord Drug Targets. 2013 May;12(3):360-70.

12 Cikla U, Chanana V, Kintner DB, Udho E, Eickhoff J, Sun W, et al. ERa signaling is required for TrkB-mediated hippocampal neuroprotection in female neonatal mice after hypoxic ischemic encephalopathy $(1,2,3)$. eNeuro. $2016 \mathrm{Jan} ; 3(1): 3$.

13 Hill CA, Threlkeld SW, Fitch RH. Early testosterone modulated sex differences in behavioral outcome following neonatal hypoxia ischemia in rats. Int J Dev Neurosci. 2011 Jun; 29(4):381-8.

14 Hurn PD, Vannucci SJ, Hagberg H. Adult or perinatal brain injury: does sex matter? Stroke. 2005 Feb;36(2):193-5.

15 Vrticka P, Neely M, Walter Shelly E, Black JM, Reiss AL. Sex differences during humor appreciation in child-sibling pairs. Soc Neurosci. 2013;8(4):291-304.

16 Jang SW, Liu X, Yepes M, Shepherd KR, Miller GW, Liu Y, et al. A selective TrkB agonist with potent neurotrophic activities by 7,8-dihydroxyflavone. Proc Natl Acad Sci USA. $2010 \mathrm{Feb} ; 107(6): 2687-92$.

17 Cheng Y, Gidday JM, Yan Q, Shah AR, Holtzman DM. Marked age-dependent neuroprotection by brain-derived neurotrophic factor against neonatal hypoxic-ischemic brain injury. Ann Neurol. 1997 Apr;41(4): 521-9.
18 Almli CR, Levy TJ, Han BH, Shah AR, Gidday JM, Holtzman DM. BDNF protects against spatial memory deficits following neonatal hypoxia-ischemia. Exp Neurol. 2000 Nov; 166(1):99-114

19 Friedman WJ, Greene LA. Neurotrophin signaling via Trks and p75. Exp Cell Res. 1999 Nov;253(1):131-42.

20 Liu C, Chan CB, Ye K. 7,8-dihydroxyflavone, a small molecular TrkB agonist, is useful for treating various BDNF-implicated human disorders. Transl Neurodegener. 2016 Jan;5(1):2.

21 Ochs G, Penn RD, York M, Giess R, Beck M, Tonn J, et al. A phase I/II trial of recombinant methionyl human brain derived neurotrophic factor administered by intrathecal infusion to patients with amyotrophic lateral sclerosis. Amyotroph Lateral Scler Other Motor Neuron Disord. 2000 Jun;1(3):201-6.

22 Thoenen H, Sendtner M. Neurotrophins: from enthusiastic expectations through sobering experiences to rational therapeutic approaches. Nat Neurosci. 2002 Nov;5(S11 Suppl):1046-50.

23 Massa SM, Yang T, Xie Y, Shi J, Bilgen M, Joyce JN, et al. Small molecule BDNF mimetics activate TrkB signaling and prevent neuronal degeneration in rodents. J Clin Invest. 2010 May;120(5):1774-85.

24 Liu X, Qi Q, Xiao G, Li J, Luo HR, Ye K. Omethylated metabolite of 7,8-dihydroxyflavone activates $\mathrm{TrkB}$ receptor and displays antidepressant activity. Pharmacology. 2013; 91(3-4):185-200.

25 Liu X, Obianyo O, Chan CB, Huang J, Xue S, Yang JJ, et al. Biochemical and biophysical investigation of the brain-derived neurotrophic factor mimetic 7,8-dihydroxyflavone in the binding and activation of the TrkB receptor. J Biol Chem. 2014 Oct;289(40):27571-84. 
26 Yang LC, Zhang QG, Zhou CF, Yang F, Zhang YD, Wang RM, et al. Extranuclear estrogen receptors mediate the neuroprotective effects of estrogen in the rat hippocampus. PLoS One. 2010 May;5(5):e9851.

27 Tabatadze N, Huang G, May RM, Jain A, Woolley CS. Sex Differences in Molecular Signaling at Inhibitory Synapses in the Hippocampus. J Neurosci. 2015 Aug;35(32): 11252-65.

28 Zhang QG, Raz L, Wang R, Han D, De Sevilla $\mathrm{L}$, Yang F, et al. Estrogen attenuates ischemic oxidative damage via an estrogen receptor alpha-mediated inhibition of NADPH oxidase activation. J Neurosci. 2009 Nov;29(44): 13823-36.

29 Dubal DB, Rau SW, Shughrue PJ, Zhu H, Yu $\mathrm{J}$, Cashion AB, et al. Differential modulation of estrogen receptors (ERs) in ischemic brain injury: a role for ERalpha in estradiolmediated protection against delayed cell death. Endocrinology. 2006 Jun; 147(6): 3076-84.

30 Dubal DB, Zhu H, Yu J, Rau SW, Shughrue PJ, Merchenthaler I, et al. Estrogen receptor alpha, not beta, is a critical link in estradiolmediated protection against brain injury. Proc Natl Acad Sci USA. 2001 Feb;98(4): 1952-7.

31 Westberry JM, Prewitt AK, Wilson ME. Epigenetic regulation of the estrogen receptor alpha promoter in the cerebral cortex following ischemia in male and female rats. Neuroscience. 2008 Apr;152(4):982-9.

32 Spencer-Segal JL, Tsuda MC, Mattei L, Waters EM, Romeo RD, Milner TA, McEwen BS, Ogawa S. Estradiol acts via estrogen receptors alpha and beta on pathways important for synaptic plasticity in the mouse hippocampal formation. Neuroscience. 2012 Jan;202:13146.

33 Shin JA, Yoon JC, Kim M, Park EM. Activation of classical estrogen receptor subtypes reduces tight junction disruption of brain endothelial cells under ischemia/reperfusion injury. Free Radic Biol Med. 2016 Mar;92: 78-89.

34 Raval AP, Bramlett H, Perez-Pinzon MA. Estrogen preconditioning protects the hippocampal CA1 against ischemia. Neuroscience. 2006 Sep;141(4):1721-30.

35 Raval AP, Saul I, Dave KR, Defazio RA, PerezPinzon MA, Bramlett H: Pretreatment with a single estradiol-17 $\beta$ bolus activates cyclic-AMP response element binding protein and protects CA1 neurons against global cerebral ischemia. Neuroscience. 2009 May;160(2);307-18.

36 Chavez-Valdez R, Martin LJ, Razdan S, Gauda $E B$, Northington FJ. Sexual dimorphism in BDNF signaling after neonatal hypoxiaischemia and treatment with necrostatin-1. Neuroscience. 2014 Feb;260:106-19.

37 Konkle AT, McCarthy MM. Developmental time course of estradiol, testosterone, and dihydrotestosterone levels in discrete regions of male and female rat brain. Endocrinology. 2011 Jan;152(1):223-35.
38 Pedersen AL, Nelson LH, Saldanha CJ. Centrally Synthesized Estradiol Is a Potent Anti-Inflammatory in the Injured Zebra Finch Brain. Endocrinology. 2016 May;157 (5):2041-51.

39 Cornil CA, Leung CH, Pletcher ER, Naranjo KC, Blauman SJ, Saldanha CJ. Acute and specific modulation of presynaptic aromatization in the vertebrate brain. Endocrinology. 2012 Jun;153(6):2562-7.

40 Pedersen AL, Brownrout JL, Saldanha CJ. Neuroinflammation and neurosteroidogenesis: reciprocal modulation during injury to the adult zebra finch brain. Physiol Behav. 2017 Apr;187:51-6.

41 Nuñez JL, McCarthy MM. Estradiol exacerbates hippocampal damage in a model of preterm infant brain injury. Endocrinology. 2003 Jun;144(6):2350-9.

42 Nuñez J, Yang Z, Jiang Y, Grandys T, Mark I, Levison SW. 17 $\beta$-estradiol protects the neonatal brain from hypoxia-ischemia. Exp Neurol. 2007 Dec;208(2):269-76.

43 Waddell J, Hanscom M, Shalon Edwards N, McKenna MC, McCarthy MM. Sex differences in cell genesis, hippocampal volume and behavioral outcomes in a rat model of neonatal HI. Exp Neurol. 2016 Jan;275(Pt 2):285-95.

44 Raz L, Khan MM, Mahesh VB, Vadlamudi RK, Brann DW. Rapid estrogen signaling in the brain. Neurosignals. 2008;16(2-3):14053.

45 Spencer-Segal JL, Tsuda MC, Mattei L, Waters EM, Romeo RD, Milner TA, et al. Estradiol acts via estrogen receptors alpha and beta on pathways important for synaptic plasticity in the mouse hippocampal formation. Neuroscience. 2012 Jan;202:131-46.

46 Arpino G, Wiechmann L, Osborne CK, Schiff R. Crosstalk between the estrogen receptor and the HER tyrosine kinase receptor family: molecular mechanism and clinical implications for endocrine therapy resistance. Endocr Rev. 2008 Apr;29(2):217-33.

47 Huang YZ, McNamara JO. Mutual regulation of Src family kinases and the neurotrophin receptor TrkB. J Biol Chem. 2010 Mar;285(11): 8207-17.

48 Razandi M, Pedram A, Park ST, Levin ER. Proximal events in signaling by plasma membrane estrogen receptors. J Biol Chem. 2003 Jan;278(4):2701-12.

49 Razandi M, Oh P, Pedram A, Schnitzer J, Levin ER. ERs associate with and regulate the production of caveolin: implications for signaling and cellular actions. Mol Endocrinol. 2002 Jan;16(1):100-15.

50 Boulware MI, Kordasiewicz H, Mermelstein PG. Caveolin proteins are essential for distinct effects of membrane estrogen receptors in neurons. J Neurosci. 2007 Sep;27(37): 9941-50.

51 Koss WA, Haertel JM, Philippi SM, Frick KM. Sex Differences in the Rapid Cell Signaling Mechanisms Underlying the Memory-Enhancing Effects of $17 \beta$-Estradiol. eNeuro. 2018 Oct;5(5):5.
52 Meng M, Zhiling W, Hui Z, Shengfu L, Dan $\mathrm{Y}$, Jiping H. Cellular levels of TrkB and MAPK in the neuroprotective role of BDNF for embryonic rat cortical neurons against hypoxia in vitro. Int J Dev Neurosci. 2005 Oct;23(6): 515-21.

53 Han BH, Holtzman DM. BDNF protects the neonatal brain from hypoxic-ischemic injury in vivo via the ERK pathway. J Neurosci. 2000 Aug;20(15):5775-81.

54 Jover-Mengual T, Zukin RS, Etgen AM: MAPK signaling is critical to estradiol protection of CA1 neurons in global ischemia. Endocrinology. 2007;148:1131-43.

55 Zou W, Fang C, Ji X, Liang X, Liu Y, Han C, et al. Estrogen Receptor (ER)-a36 Is Involved in Estrogen- and Tamoxifen-Induced Neuroprotective Effects in Ischemic Stroke Models. PLoS One. 2015 Oct;10(10):e0140660.

56 Barletta F, Wong CW, McNally C, Komm BS, Katzenellenbogen B, Cheskis BJ. Characterization of the interactions of estrogen receptor and MNAR in the activation of cSrc. Mol Endocrinol. 2004 May;18(5):1096-108.

57 Kelly MJ, Levin ER. Rapid actions of plasma membrane estrogen receptors. Trends Endocrinol Metab. 2001 May-Jun;12(4):152-6.

58 Kelly MJ, Lagrange AH, Wagner EJ, Rønnekleiv OK. Rapid effects of estrogen to modulate $\mathrm{G}$ protein-coupled receptors via activation of protein kinase $\mathrm{A}$ and protein kinase $\mathrm{C}$ pathways. Steroids. 1999 Jan-Feb;64(1-2):6475.

59 Solum DT, Handa RJ. Estrogen regulates the development of brain-derived neurotrophic factor mRNA and protein in the rat hippocampus. J Neurosci. 2002 Apr;22(7):2650-9.

60 Pérez SE, Chen EY, Mufson EJ. Distribution of estrogen receptor alpha and beta immunoreactive profiles in the postnatal rat brain. Brain Res Dev Brain Res. 2003 Oct;145(1): $117-39$.

61 Miranda RC, Sohrabji F, Toran-Allerand D. Interactions of estrogen with the neurotrophins and their receptors during neural development. Horm Behav. 1994 Dec;28(4): 367-75.

62 Champagne FA, Curley JP. Maternal regulation of estrogen receptor alpha methylation. Curr Opin Pharmacol. 2008 Dec;8(6):7359.

63 Chanana V, Zafer D, Hanalioglu D, Serebin M, Amborn KM, Frober M, et al. Role of DNA repair gene in estrogen receptor alpha expression following neonatal hypoxic ischemic encephalopathy. Poster presented at Society for Neuroscience meeting; 2018 Nov 3-7; San Diego, USA. p. 384.27

64 Hou ST, Tu Y, Buchan AM, Huang Z, Preston E, Rasquinha I, Robertson GS, MacManus JP. Increases in DNA lesions and the DNA damage indicator Gadd45 following transient cerebral ischemia. Biochem Cell Biol. 1997; 75(4):383-92.

65 Knickmeyer RC, Baron-Cohen S. Fetal testosterone and sex differences. Early Hum Dev. 2006 Dec;82(12):755-60. 
66 Kauffman AS, Park JH, McPhie-Lalmansingh AA, Gottsch ML, Bodo C, Hohmann JG, et al. The kisspeptin receptor GPR54 is required for sexual differentiation of the brain and behavior. J Neurosci. 2007 Aug;27(33):8826-35.

67 Clarkson J, Herbison AE. Hypothalamic control of the male neonatal testosterone surge. Philos Trans R Soc Lond B Biol Sci. 2016 Feb; 371(1688):20150115.

68 Sher L: Brain-derived neurotrophic factor and suicidal behavior. QJM. 2011;104:455-8.
69 Adams JH, Wigg KG, King N, Burcescu I, Vetró A, Kiss E, et al. Association study of neurotrophic tyrosine kinase receptor type 2 (NTRK2) and childhood-onset mood disorders. Am J Med Genet B Neuropsychiatr Genet. 2005 Jan;132B(1):90-5.

70 Zahn-Waxler C, Shirtcliff EA, Marceau K.: Disorders of childhood and adolescence: gender and psychopathology. Annu Rev Clin Psychol. 2008;4:275-303.
71 Brodeur GM, Minturn JE, Ho R, Simpson AM, Iyer R, Varela CR, Light JE, Kolla V, Evans AE: Trk receptor expression and inhibition in neuroblastomas. Clin Cancer Res. 2009;15:3244-50.

72 Akbarian S. The neurobiology of Rett syndrome. Neuroscientist. 2003 Feb;9(1):57-63.

73 Johnson RA, Lam M, Punzo AM, Li H, Lin $\mathrm{BR}$, Ye K, et al. 7,8-dihydroxyflavone exhibits therapeutic efficacy in a mouse model of Rett syndrome. J Appl Physiol (1985). 2012 Mar; 112(5):704-10 